\title{
REGRESSO À ILHA COM JOÃO DE MELO
}

\section{Annabela de Carvalho Rita Universidade de Lisboa / FCT}

RESUMO

Neste texto, analisa-se o modo como 0 romance de João de Melo, Gente Feliz com Lágrimas (1988), se inscreve numa tradição de escrita identitária em que o percurso individual simboliza 0 colectivo.

PALAVRAS-CHAVE: Literatura. Identidade nacional. João de Melo. Representação.
ABSTRACT

In this paper, we analyze how the novel by João de Melo Gente Feliz com Lágrimas (1988) is part of a tradition of writing about national identity in wich the individual path symbolizes the collective one.

KEYWORDS: Literature. National identity. João de Melo. Representation.

Annabela de Carvalho Rita é doutora e agregada em Literatura e professora da Faculdade de Letras da Universidade de Lisboa. Coordena 0 grupo de investigação Literatura e Cultura em InterArtes do Centro de Literaturas e Culturas Lusófonas e Europeias (CLEPUL). 


\title{
REGRESSO À ILHA COM JOÃO DE MELO
}

\author{
Annabela de Carvalho Rita
}

\begin{abstract}
Posso estar aqui, de frente para o mar dos Açores [...] e vou também percorrendo a ficção de tudo: lugares, luas, a invenção de cada movimento ou um pêndulo que oscila entre a fantasia e a vida. Posso mesmo estar sentado desde o início, tanto na primeira página de um livro como numa falésia da ponta da llha. Voltado para o Norte, que é de onde se soltam os ventos malditos e se movem as nuvens, e também de onde me chega a ilusão de nunca ter seguido senão a própria sombra.
\end{abstract}

João de Melo, Gente feliz com lágrimas

Assim começa o "Livro zero" ("A felicidade sábia") de Gente feliz com lágrimas $^{1}$, livro a um tempo anterior, posterior e transversal à escrita deste, datando-a e localizando-a ("Lumiar, 20 de Agosto de 1988"), por fim, retomando-lhe os fios que a tecem e enlaçando-os numa última palavra exclamativamente enfatizada: "literatura!" ("[...] tudo isto não passou afinal de um riso que chora ou de um pranto que ri - e de literatura!" (p. 486)).

Final que evidencia pontos luminosos alternando singularidades e semeIhanças nas brumas mnésicas da paisagem geográfica e social, mas também estética. Observarei primeiro aquela para depois a redimensionar na segunda.

No início, um canto-pranto a três vozes ainda enevoadas pela dor da rememoração alterna-as até Ihes definir a identidade em sucessivas lamentações dirigidas a um "senhor", destinatário privilegiado, protagonista e profundo conhecedor do drama do absurdo existencial, cuja voz chega a ecoar na sua suposição ("As aquisições da sua inteligência? - pergunta-me o senhor." (p. 95)): Franz Kafka (p. 97).

\footnotetext{
${ }^{1}$ Trata-se de uma obra de 1988 (Lisboa: Dom Quixote) que conquistou diversos e conceituados prémios: Grande Prémio do Romance e Novela da A.P.E., Prémio Eça de Queiroz, Prémio Fernando Namora, Prémio Cristóvão Colombo (Peru) e Prémio Antena Um. A edição utilizada foi a $16^{\text {a }}$, de Outubro de 2000, publicada em Lisboa pelas Publicações Dom Quixote. Por comodidade, todas as referências acompanharão as citações no corpo de texto.
} 
São faces de uma família cujos rostos vão esboçando, ensaiando-lhe(s) a biografia. Biografia problemática: a sucessão do fragmentário e a alternância de vozes dissolve a linearidade temporal, confundindo-a nos labirintos da memória, segundo "perpendicular[es]" paralelas à do "infinito" de Lisboa (p. 178). Em vez da cronologia, a arritmia e a necessidade da memória dolorida de certos episódios apenas deixa reconhecer fases ou épocas existenciais num puzzle sempre incompleto, lacunar e eminentemente trágico onde brilha "o fulgor retórico das imagens sobre o passado" (p. 17). O punctum agónico domina a rememoração: "O desespero do animal comunicou com o do meu pai e entrou tão fundo na minha memória como a visão de todas as tragédias até então acontecidas na família." (p. 208).

Além de dominar a existência de todos, como quando Nuno crê a morte iminente às mãos do pai:

Ergueu-me depois todo no ar [...] e devolveu-me a consciência do momento em que se morre. Vivo, percebe?, e sem a fatalidade dessa arte póstuma dos cantos fúnebres, mas assistindo de lado ao último momento da minha contingência humana. Espectador e espectáculo do meu próprio circo fantástico, com as inequívocas lantejoulas no olhar, as luminárias, as esquírolas fosforescentes, os foguetes-de-lágrimas desse terrível fogo de artifício que era a derradeira festa de estar vivo em presença do meu pai... (p. 210)

Em contraponto, alguns "episódios felizes" (p. 217), rasando de lágrimas os olhos dos seus protagonistas, retomam o título e explicam-no. Também os momentos de súbito conhecimento, quase epifânicos, constituindo saltos de crescimento, mantêm a sua nitidez:

Nunca fora tão claro como agora que se tivesse produzido em si uma súbita mudança de idade. Na infância, sofrera um impulso semelhante [...]. Quando ia fazer nove anos, sentiu-se atingido por uma estranha clarividência que fez com que, de um instante para o outro, compreendesse a aritmética do mundo. Sentira a inteligência crescer dentro de si. (p. 291)

Esses momentos "persistia[m] em si, nítido[s] e sem nenhum tempo de permeio" (p. 301), presentificados por hipotiposes mnésicas anacronizantes.

Os rostos dessa família surgem-nos em retratos. Retratos individuais que fixam, transformam e esteticizam o original:

A própria tia América [...] não hesitou em deixar-se desenhar pelo seu lápis de 
carvão. Vista ao natural, era uma espécie de cetáceo risonho, lento e de olhos azuis. Mas, entre as tabuinhas da moldura, o rosto ficou como que perpétuo sobre o busto, e o seu meio-sorriso fazia lembrar a harmonia incerta da Mona Lisa. (p. 164-165)

Mas também retratos de grupo, como um tirado por tio Martinho, recebido meses depois, no Natal, em torno do qual todos se reuniram "a tentar descobrir o importantíssimo pormenor da [sua] existência" (p. 74). Retratos onde a ficção, o símbolo e o mito se insinuam:

\begin{abstract}
Pássaros, sim, mas embrutecidos, desses que, olhando o mundo através das gaiolas de canas, se assustam com o vento, com a chuva ou mesmo com o sol que fizesse lá fora. A nossa casa era o que se pode chamar uma prisão sem grades: nela, todos vivíamos de cócoras e com medo de tudo. [...] Na opinião do papá, nunca passaríamos desses seres rasteiros e defeituosos, os pássaros, porque era necessário estar sempre a corrigir-nos e a ensinar-nos tudo de novo. So, debaixo das ordens e da voz zangada daquele domador de pássaros, fomos assumindo a condição dos animais menores [...]. Como os melros [...]. (p.185)
\end{abstract}

Retratos dos próprios retratos, envelhecidos "como uma[s] memória[s] de sombra, perdido[s] aos poucos da realidade" (p. 72). E retratos em metamorfose, como o de Nuno, que, escritor, se tornará "um homem estranhamente longínquo, cada vez mais depressivo" (p. 393) até "transformar-se no Centauro da casa" (p. 394), temido e responsável pela "definitiva destruição do conhecimento, da casa e do caminho..." (p. 410).

Equivalendo-lhes, os seus reflexos nos olhos dos outros, seus duplos no sofrimento, constituem-nos, por vezes, em inesperados espelhos identitários, operadores de autoconhecimento: "[...] quando ali chegaram os órfãos e os bastardos [,] miúdos, encardidos no aspecto, de olhar parado. [...] Quando enfrentou a solidão daqueles olhos, não teve dúvidas: estava a mirar-se a um espelho antigo." (p. 298).

Em torno deles, como nos velhos bestiários, o mundo transforma-se: o padre, por ex., é "figura litúrgica" com "o ar sobrenatural dos retratos" (p. 253) sujeita a metamorfoses animalizantes inesperadas ou sinalizadas ("águia" (p. 279), "serpente ainda sonolenta" (p. 252), "pombo" (p. 267), "cobra sinfónica" (p. 273)). E a febre causada pela dor também produzirá monstros ao ritmo de um requiem:

Mergulhei, assim, num tumulto de sonhos reais, separado do mundo pelas 
paredes de vidro do delírio e da agonia. [...] Monstros vagarosos semelhantes a cavalos incendiados e suspensos no ar, entravam em mim sem que o seu fogo me queimasse. E rodas dentadas, passando-me pelo corpo, não logravam trucidar-me. E nuvens bicudas, apesar de espetadas sobre mim como cornos de bois, continuavam apenas a flutuar-me na carne e no espírito. A chuva era ainda escura, imponderável e ácida como a grande noite vazia e intemporal. (p. 213)

Também os rodeia a rejeição e o escárnio de todos, extensão dos sentimentos que dedicam ao pai, de quem se tornam, assim, duplamente vítimas:

Quando passávamos, éramos sempre os filhos do Cão, os filhos do Carrasco, os filhos do Emanoel Demónio [...]. Filhos dele, [...], mas também culpados das suas culpas e acusados dos seus defeitos. Sem nenhuma possibilidade, no juízo desta gente, de sermos afinal as suas primeiras vítimas. (p. 233)

Como por acção de um prisma, a decomposição desse choro familiar em três vozes unifica-se, cedendo ao protagonismo de uma dita n' "a $3^{a}$ pessoa do singular" ("Livro Segundo"), assim "ausentada" no discurso da família em dissolução e equacionando a problemática da escrita e da despersonalização nela implicada, pessoa que contra-dialogará com o seu par afectivo, dando conta do ciclo de amor e desamor de ambos, pessoa progressivamente vertida na primeira, que o "Livro Zero" confirmará e legitimará.

No centro do retrato da família, "puzzle sagrado que era preciso aprender a montar a partir das suas peças primordiais" (p. 322), matéria de Gente Feliz com Lágrimas: os pais. Centro de desafecto, inscrevendo-o no destino de todos como uma maldição:

Extrair da alegoria da família a lição moral, estabelecer-lhe uma síntese. Fá-lo então pensando que ele e os irmãos continuam a debater-se com o único problema das suas vidas. Todos se ressentem ainda de uma inexplicável ausência de colo materno. Essa maldição está-lhes no sangue, como um veneno, e atravessa agora a quarta geração. (p. 362)

Centro dominado por uma figura totémica que a velhice e a distância transformarão num "daguerreótipo de família" (p. 154): "Na verdade, sempre foi tão monarca que depressa nos fez perder o pudor respeitoso com que os outros filhos veneram os pais. A nossa existência foi-se extinguindo na sua presença, como que minada por essa fatalidade." (p.49). E esvaziado da mãe:

Não havia mãe. A minha foi sempre uma mulher longínqua e de pouca opinião. 
Ralhava de longe, de onde fazia as camas ou levava um balde com caldo de farelo e cascas de batata à gamela dos porcos, mas não creio que o fizesse por si. $\mathrm{O}$ amor dessa mulher pautou-se por uma estrita, plana ou mesmo côncava obediência ao seu homem. De resto, a família foi como uma ninhada confusa, crescendo ao ritmo do cio dele. (p. 51)

Ausente, ela adquire consistência com o afastamento dos filhos, acabando por se consubstanciar na Morta, onde a viuvez se encontra com a morte anunciada, ritualizando-se:

Chamara-me com a fatalidade desse gesto soturno, um gesto que oscilava entre a fadiga extrema de estar viva e a vespertina lucidez dos moribundos. Subi as stairs a correr, ajoelhei-me a seus pés, quis possivelmente dar-lhe as mãos e assistir assim ao suspiro da mulher que sempre se constituíra no grande enigma da minha vida. Então, como se a realidade dela me estivesse sendo devolvida por um espelho viciado, vi nos seus olhos a perfeita, absurda, decerto enigmática evidência da morte. (p. 371)

Nesse ritual, a liturgia exprime o desejo de eternidade, de preenchimento do vazio amoroso:

Não se habituaria nunca à ideia da despedida. [...] Queria outro perdão, e ficar eterna em mim como a casa, a terra, o mar e as luas da minha infância - e esse perdão sem lágrimas nem mentiras só eu, e não ela, o poderia realizar. Sabia, disse-me, que a minha anterior existência continuava atravessada, funda como uma âncora, nas sombras do ressentimento e da vergonha. Na verdade, disse, [...] Esqueci-me de tudo a teu respeito [...]. (p. 373-374)

Fugindo desse centro, a segunda geração dispersa-se pelo mundo, na diáspora da emigração, cumprindo a ordem bíblica "Crescei e multiplicai-vos!" e observando a sua relação fragilizar-se na sintaxe das cartas através das quais comunicam:

[...] a cadeia que nos unia e tornava irmãos foi-se fazendo frágil. Com a minha partida e a partida de Nuno, quebraram-se os primeiros elos dessa união. Começávamos a dispersar-nos, a dissolver-nos em mundos separados. A nossa existência passou a ser feita de cartas, erros de ortografia e parágrafos mal compreendidos que era preciso explicar na carta seguinte. (p. 97)

Fragilidade e dissolução evidenciadas quando das partilhas da herança dos pais a que Nuno Miguel assiste "em pânico" (p. 175-178), emergindo da 
"penumbra" desse "teatro" com "a casa cresce[ndo] por cima da [sua] vida" (p. 177), habitada por sombras que fazem dele "o primeiro e único morto da família que ainda não morreu" (p. 179), autor denegado da história comum.

A viagem de fuga para Lisboa ou para o estrangeiro é sempre encarada como uma caminhada em direcção à luz, a "uma terra há muito prometida" (p. 105):

Ainda hoje não sei, não consigo acertar com o vocabulário que melhor se ajuste a descrever o mercúrio das trevas a alto-mar, nessa tenebrosa viagem entre Ponta Delgada e a luminosa Lisboa. Tudo se confunde de resto com as águas turvas e o tempo sombrio da infância. (p. 88)

Com a distância, as presenças e as paisagens do passado fixam-se e enevoam-se, suspensas numa espécie de limbo de uma memória visualizadora, arrancadas ao continuum temporal. Algumas, fantasmagorizam-se em imagens generalizadoras, como a guerra: "Aprendi tudo: a matar pelo medo de morrer, a fazer de conta que era tudo mentira, a supor que se estava apenas no carnaval do inferno e que todos tinham de ser demónios e anjos ao mesmo tempo." (p. 203).

Mas, mesmo longe, é uma geração marcada por essa origem:

O caso é que eu, ao contrário dos meus irmãos, deixei-me levar por uma frase obsessiva, a única que me ocorre acerca do mundo em que ele nos pôs a viver. Sinto-a num turbilhão, a minar-me os primeiros cabelos brancos e a estreitar os minúsculos espaços que ainda separam as primeiras rugas do rosto [...]. Se the dissesse que tive um pai verdadeiro, o espírito reagiria logo aos mecanismos da inteligência e da razão. Mas defini-lo tão-só como 'um grande cão de pai' e consentir que você vá depois transcrevê-lo, ipsis verbis, no livro que veio aqui escrever, é talvez incorrer numa contra-natura. Ou seja, posso estar apenas devolvendo à memória dele a mesma crueldade moral e uma falta de escrúpulos idêntica à que ele exerceu sobre nós. Incomodam-se tanto os negócios do coração como a censura medieval dos meus irmãos parados no tempo: cresceram, foram-se embora daqui, mas mantêm-se ainda naquela atitude religiosa dos domingos de missa - místicos, assustados com a vida e definitivamente órfãos de pai e de mãe. (p. 48)

\section{Origem onde se geram cisões aparentemente inexplicáveis:}

Não cheguei a perceber por que motivo no decurso desses três anos, morando nós juntos, de frente para o rio da mesma cidade perigosa, comendo do mesmo lodo e bebendo das águas turvas desse tempo de Lisboa, vivemos sempre afinal 
em margens opostas. Calados e estranhos. Sem ódio nem superiores desavenças. Mas de costas voltadas um para o outro [...]. (p. 98)

Porém, a morte desse centro, par original cuja relação os descendentes vão declinando como podem, acontecerá de modo diferente, embora conduzindo sempre à reconciliação dolorosa.

No caso de Nuno, a reconciliação com o pai ocorrerá aquando da visita à sua campa, vivida como uma espécie de incorporação:

Colocou os dedos sobre o bronze da lápide, que the parecia agora translúcida como um vidro fumado [...]. [...] Através desse vidro de bronze, pode apenas imaginá-lo descarnado, dum verde quase vegetal, como numa foto antiga. [...] E os ossos desse morto, que possivelmente se move ainda à procura da completa $\mathrm{e}$ definitiva imobilidade, estremecem dentro de Nuno. Mergulham, afundam-se, naufragam, indo ao contrário das vozes e na direcção do silêncio. A dor é assim uma nuvem perdida, e vem de dentro para fora. Por um instante, sente que ela se afia em si, num qualquer órgão ainda inlocalizado do corpo. Depois é como se se tivesse convertido numa lâmina cega. (p. 370)

Com a da mãe, Nuno experimentará primeiro o irreconhecimento no encontro com ela:

Recusa-se a revê-la assim, figura de barro mirando-se na água enegrecida pelas nuvens. Procura os olhos azuis de outrora, os negros cabelos vivos, a brancura acetinada da pele do pescoço, muito ponteada pelos sinais. Mas no sítio onde devia haver um corpo de garça pousada no ninho, só é possível vislumbrar a morte sentada num trono aveludado. (p. 313)

Essa morte, a última do par, reunirá as três gerações e os seus tempos:

[...] quando o movimento de aproximação se torna recíproco e inevitável, Nuno começa a viver a troca desses dois mundos [o de Lisboa e o que está do outro lado do oceano]. Agora, é como se atravessasse a última ponte e vencesse o nevoeiro desses tempos que se cruzam e vão fundir-se numa terceira realidade. (p. 338)

Trata-se de um encontro marcado por uma liturgia que conduzirá o herdeiro designado ao templo da casa familiar, cuja construção "é um dos episódios mais luminosos da infância" (p. 89), lugar de reconciliação, encontro, surpresa e esclarecimento.

Nela penetrará Nuno como em lendário castelo da Bela Adormecida, 
buscando reconhecer o "templo rosado da infância" (p. 460) no "templo defunto" (p. 462), muito mais do que os seus antepassados ficcionais (caso da dinisiana Casa Mourisca, evocada, aliás (p. 457), ou o queirosiano Jasmineiro, por exemplo):

Quando a porta rangeu sob o impulso do joelho, ficando apenas entreaberta, tiveram início as surpresas. Não tinha pela frente o templo rosado da infância. [...] Só dobradiças perras, um último ranger das ferragens e a quase total ausência de luz. [...] Os azulejos do chão do corredor tinham sido submersos por uma espécie de líquen e as ervas despontavam já das frestas. [...] Apresentou-se-lhe então o opressivo, o tormentoso, o excepcional espectáculo de uma casa há muito fechada, consumida pelo abandono [:] [...] as flores funestas da humidade, a debandada dos ratos por dentro das ripas do tecto, o cheiro do mofo e dos bolores cozidos que indicavam já o apodrecimento das paredes e dos móveis. [...] Sobretudo aquele cheiro apodrecido, do qual não havia memória, tornara-se-lhe insuportável. (p. 460-461)

Mais chocante ainda será para ele ver os sinais da "profanação desse templo defunto" (p. 462). Aí, na "solidão e [...] desgraça dessa memória difusa, dividida entre a realidade e a ruína da casa" (p. 462), se fundirá com a casamãe, identificado com ela: "Para Rui Zinho, porém, a casa era ele mesmo, mas na primeira pessoa do singular. Soubera sempre que um dia viria não para habitá-la, e sim para a viver." (p. 459). Aí se reencontrará com o resto da tribo familiar, sinédoque e símbolo dela, mas também imagens onde o remoto se verte em genealogia:

Quando se lhe perfilam na frente, as tias começam por ser apenas corpos decrépitos, ruças e demasiado solenes na sua postura distante. [...] Não restam a Nuno grandes dúvidas: está perante os seus antepassados. Nelas, tudo é tão remoto como isso, como o vento que trouxera até ali os seus esqueletos ressuscitados, o mesmo que em breve os levaria de volta aos ninhos errantes e aos sítios onde a morte existe ou se anuncia. (p. 473-475)

Genealogia onde se inscreve a especularidade, assemelhando e diferenciando: "O contraste perfeito dessa mulher próspera e impetuosoa podia ser mirado no espelho invertido da tia Sónia." (p. 476). Genealogia que se esfuma em longínquo e indeciso ponto de fuga:

Da parte da mãe, eram numerosas as ausências, tanto da vida como do Rozário. Os tios tinham sido levados pela grande vaga da emigração para Toronto, 
Vancouver e Boston, a seguir ao vulcão dos Capelinhos. Tia Flórida morrera de asfixia, vítima de uma pneumonia dupla, se bem estava recordado, ou talvez de cancro, ou mesmo de um enfisema, como acontecera com vavô Botelho: a memória dessas mortes era tão remota quanto a nuvem iluminada do princípio da idade. (p. 477)

Genealogia que chega a fornecer hipóteses perspécticas potenciadoras de ficção, insinuando temas de eventuais livros futuros e provocando no leitor a suspeita de que tal eventualidade encobre uma concretização presente ou, mesmo, pretérita:

Na opinião de Zinho, a mãe de Nuno pertencia ao número dos vivos atormentados pela saudade do futuro. Se um dia pudesse inventar uma fábula acerca dessa mulher misteriosa, teria de imputar-lhe uma existência dividida entre o amor do seu homem e uma estranha e talvez enigmática paixão pelo destino dos filhos. (p. 472)

Hipóteses também acenadas por elementos da segunda geração, como acontece com Maria Amélia:

O caderno da minha vida passada, senhor, encheu-se de páginas e páginas de abandono, escritas pela inquietação e emendadas em muitos dos seus erros. Desfolho-o com grande desencanto, e essas memórias inúteis não são mais do que notas de rodapé ao fundo da história da minha família. (p. 222)

Aí se surpreenderá na foto da contracapa de um livro seu com "o ar errático e pretensioso, a fealdade e o despudor de um rosto assustado, e a falsa modéstia, a sua e a de todos os escritores do seu país" (p. 462), denunciando de novo a sinédoque, o símbolo e o emblematismo na sua relação com o colectivo e implicando-os numa outra, sugerida, entre real e ficcional: "[...] Nuno fala por si e por todos." (p. 363). Por vezes, esse colectivo restringe-se no tempo e expande-se no social, exprimindo-se na ideia de geração:

A minha geração acabou com a guerra de África, perdoou os esbirros e devolveu ao povo português o céu diáfano do seu país escuro. Pode morrer de consciência tranquila: deu o seu salto mortal no trapézio, caiu de pé, não venha ninguém dizer-lhe que o circo vai nu ou que são falsos o Sol, o mar, os dias de agora e os que a estes hão-de seguir-se. (p. 88-89)

Ou conflui para o sentimento de "homem açoriano" (p. 330). Outras vezes, 
expande-se maximamente no tempo e no espaço: "Vira tudo. [...] Agora tinha a sensação de ter vindo [...] de todas as cidades perdidas no tempo." (p. 472). E, assim, anuncia o que João de Melo reivindicará em Açores, o segredo das ilhas:

\begin{abstract}
Não sei se faz sentido falar dos Açores como de ilhas perfeitas; mas nelas mora um povo que descende de toda a memória portuguesa, e cuja experiência de insularidade the confere uma identidade anímica e cultural muito própria. Ela vem tanto da história dos séculos e do povoamento, como dos seus mitos de sempre: a solidão marítima e a visão da ilha em frente, a unidade e a diversidade de uma paisagem em confronto ou em síntese de grandeza, o tempo que entre na alma, a fé numa eternidade feita à medida de cada homem. ${ }^{2}$
\end{abstract}

Indivíduo, casa, ilha, país e literatura sobrepõem-se, habitando-se mutuamente, fazendo-se pressentir na transparência das suas imagens e implicando em si uma íntima relação entre ficção e real, ambos tensionados entre a asfixia existencial e o sonho de um além compensatório.

Aí se reconhecerá, por fim, "um homem suspenso", anunciando um livro ainda a vir depois de ter sentido em si a gestação do "livro aberto" (p. 110), "deste livro" (p. 318), que protagoniza sob um nome em metamorfose (Nuno Miguel, Nuno, Nuno Zinho) e uma deixis instável (da primeira à terceira pessoas), na casa de espelhos que é o discurso, onde os reflexos se confundem, invertem e duplicam labirinticamente, pondo em causa identidades, estatutos, instâncias, original e imagens, desenvolvendo reversibilidades:

\begin{abstract}
Era impossível que a ele, Nuno, isso sucedesse agora e fosse mesmo a sua vida. Nos livros de Rui Zinho, sim, essa fatalidade ocorrera na pessoa de outrem. $\mathrm{O}$ pior é que Nuno só agora admitia estar finalmente vivendo uma das histórias inventadas pelo seu duplo. Mas a sua ingenuidade consistira em pensar que Rui Zinho seria sempre e apenas um pseudónimo. Eis senão quando tudo se inverte: Zinho é a premonição de Nuno, o seu lado maldito, e Nuno é posto a viver duas vezes, pelo sofrimento da ficção e da vida. Nunca nenhum livro custou tanto a Rui Zinho escrever como este. E é um facto que escrever na primeira pessoa é como morrer num tempo e não saber nada do tempo seguinte. (p. 472)
\end{abstract}

Ou confessa toda a dramatização, iluminando definitivamente o nome que a capa consagrará (João de Melo) e ambiguizando o estatuto da ficção (romance? biografia? autobiografia?):

\footnotetext{
${ }^{2}$ MELO, João de. Açores, o segredo das ilhas. Lisboa: Dom Quixote, 2000, p. 7.
} 


\begin{abstract}
Anos mais tarde, Rui Zinho, que é seu duplo, sente o mesmo frio descer-lhe pela espinha. Tenta converter esse arrepio no impulso e no fio que há-de conduzir a sua escrita. Não consegue. Na verdade, existe no meio de ambos um terceiro indivíduo. Esse trocou todos os nomes, inventou fisionomias, reuniu em Nuno e em Rui Zinho a mentira da sua despersonalização e vai deixar outro nome escrito na capa deste livro... (p. 318)
\end{abstract}

Ambiguidade que Marta, personagem, confirma, revelando a inversão da relação entre vida e obra, procurando Nuno nesta por tê-lo perdido naquela:

\begin{abstract}
E como perdi o sinal de si e o conhecimento da sua mudança [...] [e]studei-a sempre nas personagens a que você pôs nomes falsos e que afinal não passavam nunca de fragmentos da sua multiplicidade. Você multiplicou-se a si mesmo pelos homens cinzentos que figuram, desfilam e se repetem nos seus livros. Multiplicou-me também a mim [...]. (p. 390)
\end{abstract}

"E [passou-se] para aquilo a que deixou de chamar 'a minha obra' e passou a designar por 'a minha vida'." (p. 422).

Tudo isso cria uma interdiscursividade que dissolve as fronteiras entre as obras de João de Melo, imbricando-as através de nexos por onde transitam imagens, temas, obsessões, fantasmas, paisagem da escrita onde os títulos ensaiam frases identitárias de uma escrita continuada, de uma ficção em autoefabulação gerada na "sofrida autobiografia d[a] infância" (p. 392): eu sou um homem suspenso (1996) entre pássaro e anjo (1987), um olhar português (1991) buscando na navegação da terra (1980) o segredo das ilhas (2000), da Ilha, nova Ítaca de moderno Ulisses (p. 177), fazendo a autópsia de um mar de ruínas (1984), sofrendo a dolorosa convição de que o meu mundo não é deste reino (1983), "escrevivendo" o livro da minha gente feliz com lágrimas, saga familiar com a social em contra-luz...

No alongamento e na respiração da frase, os títulos adquirem novo sentido, convocando outra paisagem que os excede, antecedendo-os também, que excede o próprio literário, paisagem estética onde as artes se respondem: a literatura (com a sua Ítaca mítica, homérica (p. 177), Baudelaire (p. 397), Júlio Dinis (p. 457), etc.), o cinema (A Cidade Branca, de Alain Tanner ( $p$. 334), Filhos dum Deus Menor (p. 401)), a pintura (Os Domingos de Lisboa (p. 178), Malhoa (p. 304)), a música (Mozart (p. 348)). A paisagem humana, geográfica e episódica de Gente feliz com lágrimas vai convocando outras que a reflectem, modalizam e universalizam, dotando a ficção de polimorfismo e 
intermedialidade, insinuando-a como um teatro de sombras de outras representações.

Por sua vez, títulos e imagens alheios também se diluem na paisagem do seu discurso, pontuando-a de luz refractada, reflectida: "A minha geração [...] caiu de pé" (p. 88), evoca As árvores morrem de pé, de Alejandro Casona, "um simples bicho da terra" (p. 205), lembra Torga, "casados, tínhamos medo de Virgínia Wolf" (p. 413), cita Quem tem medo de Virgínia Woolf?, de Edward Albee, etc, etc.

Uma dessas imagens, recorrente e diversamente manifestada, é a dos "pássaros", que referi atrás, com que identifica a família e cada um dos seus elementos. Com eles, desdobra-se um diversificado intertexto marcado pelo sofrimento e pela dor nas suas diferentes modalidades, combinados com o isolamento, o enigma, a estranheza, a frustração e/ou o suspense: Os pássaros (1952) de Daphne du Maurier trabalhados pela câmara de Hitchcock (1963), os de Colleen MucCullough (Pássaros feridos, 1977), mas igualmente os de António Lobo Antunes (Explicação dos pássaros, 1981), os de Orlanda Amarílis (Ilhéu dos pássaros, 1982), etc. Convocam também o imaginário místico, cristalizado em textos como A linguagem dos pássaros, sufi, de Farid ud-Din Attar, ou uma dimensão mais estética, de "meditações poéticas", como a de Saint-John Perse (Pássaros, 1962), de artes plásticas, etc. O tema da paixão e morte vertidos em dolorido canto final atravessa o imaginário colectivo, em mitos, lendas, histórias infantis, etc, com destaque, na literatura, para o rouxinol em que o poeta se reconhece, figura sustentando uma longa genealogia cuja diversidade não elimina a familiaridade. Aqui, exprime-o esse canto agónico e sublime onde o coro e o solo se conjugam até ao esgotamento.

$E$, apesar de não serem enunciadas, outras evocações me assaltam, em especial, a d'O quarteto de Alexandria, tal como Durrell o apresenta, explicando a sua arquitectura, espelho fumado onde reconheço analogias (ressalvando as diferenças):

[...] tentei realizar um romance em quatro dimensões cuja forma assenta no princípio da relatividade. [...] Os quatro romances obedecem a este plano. Contudo as três primeiras partes devem desenrolar-se no espaço (daqui utilizar o conceito de 'sósia' onde se podia esperar continuação) e não se encadeiam numa série. Sobrepõem-se, entrecruzam-se, mas as relações entre elas são puramente espaciais. $\mathrm{O}$ tempo fica em suspenso. Somente a quarta parte representa o tempo e constitui verdadeiramente uma continuação. A relação sujeitoobjecto é tão essencial à relatividade que tentei conduzir o romance simultane- 
amente na forma subjectiva e objectiva. A terceira parte, "Mountolive", é um romance [...], no qual o narrador de Justine e Baltasar se torna num objecto, isto é, numa personagem. ${ }^{3}$

Através dessas referências que redimensionam as históricas (sociais e políticas), Gente feliz com lágrimas conquista um fundo difuso que esfuma os contornos das personagens e das suas histórias, ecos e projecções da História comum, adensando fantasmas estéticos cuja presença mais se vai fazendo sentir, e que esteticiza ainda mais o discurso. Entre os planos assim multiplicados, a consonância reforça as linhas de sentido nucleares da ficção e confirmaa como construção de segundo nível, discurso de discursos tecido, definindo a sua identidade na alteridade, no diálogo com outros textos do seu autor e de autoria alheia, expandindo a letra à arte em geral, imbricando subtilmente uma na outra.

Por exemplo, a múltipla referência aos "domingos de Lisboa" evoca, irresistivelmente a pincelada cesárica e a sua Lisboa entre a luz ("Num bairro moderno") e as sombras ("O sentimento dum ocidental"), sombras por onde Gomes Leal arrastou a fome e o choro de um Camões doente, cidade que António Boto afadista com "vielas da desgraça" (Canções, 1921), que Bernardo Marques populariza no Diário de Lisboa (1925-29), que Almada Negreiros torna trepidante de vida nas "fotografias com a imaginação" (Nome de guerra, 1938) ou geometriza, vincando a emigração (Domingos em Lisboa, 1946-49), tema também de Malhoa e de António José Patrício (A despedida, 1858), domingos que O’Neill considera "terríveis de passar" pelos rituais do quotidiano (No reino da Dinamarca, 1958), etc. A íntima solidão, melancólica e fascinada, de um autor movimenta-se nesse cenário urbano que representa o que o engloba, anelante de um leitor a quem "confessar-se" e de quem, afinal, fala: Portugal. Vulto habitado de outros também vertidos em arte.

Do drama da gente feliz com lágrimas que a Literatura verte em cantopranto, eleva-se e define-se um solo na lenta elaboração do símbolo e da sinédoque: o de um sujeito autoral que, a tracejado, vai esboçando um itinerário estético de timbre agónico duplo e sequência do que atravessa, também a tracejado, a própria literatura nacional (Gil Vicente, Bernardim Ribeiro, Camões, Cesário Verde, António Nobre, Raúl Brandão, Fernando Pessoa, Vitorino Nemésio, Sofia, Vergílio Ferreira, etc) ou outra que com ela partilhe essa

\footnotetext{
${ }^{3}$ DURRELL, Laurence. Baltasar. Lisboa: Ulisseia, 1991, p. 5-6.
} 
identidade ocidental que, desde Homero, "de frente para o mar", se vai pensando e transformando, volumetrizando-se nessa trajectória e revelando consubstancial polifonia (Jorge Luís Borges, Pablo Neruda, Hérib Campos Cervera, etc). Nas sombras do efabulatório ("fábula" (p. 362)), a palavra de João de Melo, unificada pela interdiscursividade (memória, continuidade e metamorfose), vai-se inscrevendo nessa profunda, sinuosa e continuada reflexão sobre uma identidade estética onde se fundam indivíduo e país que a Literatura, como e com as outras artes, desenvolve e elabora. 